\title{
Research Paper: The Effect of Yoga on Musculoskeletal Pain in Elderly Females: A Clinical Trial
}

Tayebeh Mirzaei $^{1}$ (D), Omolbanin Tavakoli' ${ }^{1}$, Ali Ravari ${ }^{1^{*}}$ (iD

1. Department of Medical Surgical Nursing, School of Nursing and Midwifery, Geriatric Care Research Center, Rafsanjan University of Medical Sciences, Rafsanjan, Iran.

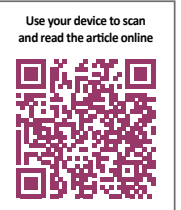

Citation Mirzaei T, Tavakoli O, Ravari A. The Effect of Yoga on Musculoskeletal Pain in Elderly Females: A Clinical Trial. Iranian Rehabilitation Journal. 2022; 20(Special Issue):55-64. http://dx.doi.org/10.32598/irj.20.SpecialIssue.1512.1

doíhttp://dx.doi.org/10.32598/irj.20.SpecialIssue.1512.1

Article info:

Received: 23 Jun 2021

Accepted: 08 Nov 2021

Available Online: 01 Jan 2022

\section{Keywords:}

Yoga, Musculoskeletal pain, Aging, Elderly, Iran

\section{ABSTRACT}

Objectives: Chronic musculoskeletal pain is a common problem in the elderly. Yoga exercise can be considered a non-pharmacological and complementary method for pain control. The present study was conducted to investigate the effect of yoga on chronic musculoskeletal pain in elderly females referring to selected health centers in Rafsanjan, Iran.

Methods: In this clinical trial, 60 females over 60 years of age with musculoskeletal pain were randomly divided into two intervention and control groups. The intervention group received three one-hour training sessions weekly for eight weeks, and they did yoga for 1 hour in each session. The pain was measured in both groups before the intervention and at weeks four and eight using the McGill Pain Questionnaire. The control group did not receive any special intervention

Results: The mean musculoskeletal pain decreased at the end of the 4th and 8th weeks after performing yoga in the intervention group compared to the control group $(\mathrm{P}<0.005)$. The subscales of sensory dimension and severity of pain showed no decrease after four weeks compared to the control group $(\mathrm{P}>0.005)$. However, at the end of the eighth week, all the pain subscales decreased in the intervention group $(\mathrm{P}<0.005)$.

Discussion: The obtained results revealed that practicing yoga continuously could reduce musculoskeletal pain in elderly females; thus, it is suggested that such yoga exercises be included in the treatment of musculoskeletal pain in this group.

\section{* Corresponding Author: \\ Ali Ravari, PhD.}

Address: Department of Medical Surgical Nursing, School of Nursing and Midwifery, Geriatric Care Research Center, Rafsanjan University of Medical Sciences, Rafsanjan, Iran.

Tel: +98 (34) 34255900

E-mail: ravary4776@yahoo.com,dr.ravari@rums.ac.ir 


\section{Highlights}

- Both four weeks and eight weeks of yoga practice reduced the mean musculoskeletal pain in elderly females.

- Four weeks of yoga practice did not reduce the subscales of sensory dimension and severity of pain in elderly females.

- Eight weeks of yoga practice reduced all the subscales of pain in old females.

\section{Plain Language Summary}

Old age is a critical period of human life, and chronic musculoskeletal pain in the elderly is highly prevalent. Yoga is a popular complementary or alternative therapy for musculoskeletal pain. Limited studies have evaluated the effects of yoga for the treatment of chronic pain and they have been conducted over a limited period of time or their results are not entirely consistent in elderly patients. This study examined the effect of yoga on chronic musculoskeletal pain in elderly females. The results suggested that continuous yoga exercise can reduce chronic musculoskeletal pain in elderly females.

\section{Introduction}

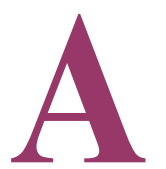

ging is a natural phenomenon associated with changes in the old person's physical, mental, and social aspects of life [1]. Health advances, industrialization, changes in lifestyle, and environmental factors have contributed to increased longevity and life expectancy in the last few decades [1]. In the following decades, the elderly population in the world will be increased and show a different perspective [1]. In this regard, Iran also is a country that moves from a young to a middle-aged population and will soon join the number of old-population nations [1].

By increasing the age, the risk of one or more chronic diseases increases as well [2]. Chronic pain is a serious threat to the health of the elderly [3]. Approximately one-third of the elderly suffer from chronic pain, which is mainly caused by arthritis, osteoporosis, and vascular disorders [2]. The presence of chronic pain among the elderly leads to increased costs for society and low quality of life [2].

Taghipour et al., in their study on the elderly in Amir Kola, reported a prevalence of $82.4 \%$ for musculoskeletal pain over the past six months, with a prevalence of $76.2 \%$ in men and $89.9 \%$ in females [4]. It was also reported that one-third of the old people living in the elderly houses and at the community level suffer from the pain [3]. Chronic musculoskeletal pain is more common in females than in men, which can be due to differences in the level of sex hormones [5]. Taghipour et al. also indicated that the prevalence of pain in old females in all upper and lower organs and head and neck areas are higher than that in men [4].

Chronic musculoskeletal pain is recurrent and is caused by problems in bones, joints, muscles, and soft tissues [6]. Pharmaceutical treatment is often considered a selective treatment for chronic pain [7]. Considering the multiple complications of medications and pharmacokinetic and pharmacodynamics changes and the presence of underlying illnesses in the elderly, non-pharmacological pain control should be considered in this age group [7]. Studies have been conducted on non-pharmacological interventions to control chronic pain in old people, including Pilates [8] and massage therapy, yoga, and tai chi [9].

Researchers believe that Pilates exercises can positively affect depression and happiness in the elderly [8]. It has been proven that the elderly can adapt to fitness exercises and develop their physical capacity [10]. Old people are not able to perform conventional exercises due to muscle atrophy and weakness in the musculoskeletal system, and the probability of their injury following these exercises is high. Hence, yoga is preferable to other sports for these people [10]. Recently, the effectiveness of yoga exercises in the elderly was taken into account by the researchers. These exercises are a combination of physical and mental exercises concentrating on movement control, body position, and respiration [9].

Studies have recently focused on the effects of yoga exercise. For instance, the effects of yoga on pain relief and increasing the range of motion in females with lumbar disc herniation [11] and pain, back flexibility, depression, also its effects on serum serotonin levels and neurotroph- 
ic factors in females with a chronic backache have been reported [12]. Also, some review studies have shown the effectiveness of yoga as a treatment for musculoskeletal disorders [13, 14]. However, in some studies, the effect of yoga on backache in old females over 65 years old was not reported [15]. Moreover, yoga was effective on knee pain caused by osteoarthritis in the elderly [16].

The results of studies on the effectiveness of yoga on elderly patients are not completely consistent. Although some studies have indicated the effectiveness of yoga $[11,12]$, some others have shown that yoga exercises have no positive effect on the relief of elderly patients' pain [15]. Numerous studies have been conducted on a particularly painful position, such as pain in the waist, knee, neck, or other areas of the body $[12,16]$. However, many elderlies experience pain in different areas of their body, including knees, hands, feet, neck, and waist. Furthermore, considering the different lifestyles of the elderly in Iran [17] and the possibility that different areas of the old people's bodies may be affected by the chronic pain, further studies are definitely needed in this area. Hence, the research team decided to evaluate the effect of Yoga on musculoskeletal pain in elderly females.

\section{Materials and Methods}

\section{Participants}

The present study was a randomized clinical trial (IRCT20150519022320N11) performed on 75 elderly females referring to Health Services Center No. 1 and health centers under the control of this center, in Rafsanjan City, from 22 April 2017 to 20 December 2017. Inclusion criteria were female gender, age over 60 years, the ability to perform yoga exercises without the inability to exercise, and having a minimum literacy. People with musculoskeletal pain less than three months, pain intensity less than three based on Visual Analogue Scale (VAS) criteria, Parkinson's disease, Alzheimer's disease, recent fracture, drug addiction, the history of mental illness or the use of psychosocial drugs, admission to the psychiatric ward, other sports and exercise prohibitions, were not included in the study. Exclusion criteria were the use of other pain relief treatments, unwillingness to continue the program, fracture occurrence, start of taking narcotic drugs, absence in $25 \%$ of yoga trainings. Based on the exclusion criteria, eight individuals were excluded from the intervention group: two due to unwillingness (in the fourth week), three due to the absence of excessive permission, one due to the start of surgical treatment, and

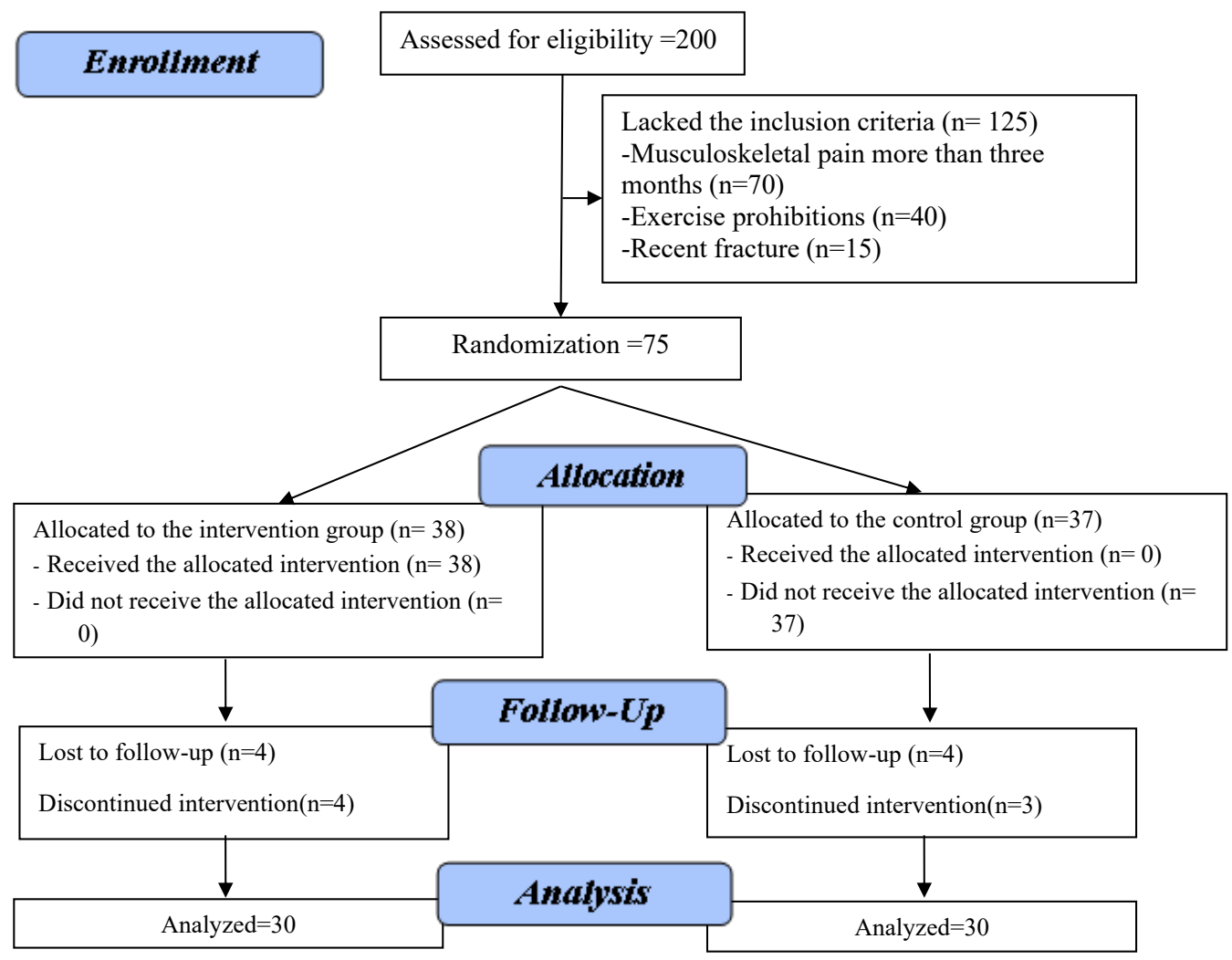

Figure 1. Flow diagram of the study protocol 
two due to traveling (in the eighth week). Also, seven patients were excluded from the control group: two cases due to reluctance to continue to cooperate (in the fourth week), three due to the start of the new treatment, and two due to bone fracture (in the eighth week) (Figure 1). It is noteworthy that the trained person evaluated the participants based on the inclusion and exclusion criteria.

\section{Intervention}

The research procedure and the fundamental objectives were fully explained to the subjects, and written informed consent was obtained from the participants. The sample size was determined to be 28.6 people in each group using the statistical formula and considering the standard deviation of 1.4 , the significance level of 0.05 , the power of $90 \%$, and the effect size of 1.2 , and 30 cases were considered for each group for more confidence [11] (Equation 1).

$$
\text { 1. } n=\frac{2\left(z^{1}-a / 2+z_{1-\beta}\right)^{2} \delta^{2}}{d^{2}}=28.6
$$

There were 700 records of elderly females in these centers, of which 200 were selected by the simple random sampling and were contacted, 125 lacked the inclusion criteria (70 having musculoskeletal pain for more than three months, 40 having exercise prohibitions, and 15 having a recent fracture). The remaining 75 patients with self-declaration of musculoskeletal pain [18] were selected. Then, they were randomly assigned to the intervention (38 people) and control (37 people) groups (Figure 1).

\section{Data collection}

The pain questionnaire was answered by the elderly who were educated and completed for the illiterate ones by the club's secretary. First, demographic information, including the level of education, occupation, economic status, and other information of the questionnaire, including the history of fracture, history of hospitalization for other causes, and taking drugs to control the pain, were questioned and recorded, and the height and weight were measured.

The intervention group was then supervised by a trainer experienced with the elderly with a valid degree (the document was observed, and its copy was kept at the gym). Yoga was done within three 1-hour sessions weekly for eight weeks. The exercises were done in the morning after a brief breakfast. After attending the gym and wearing bright clothes (according to the trainer's instructions), the mats were put with the supervision of the researcher and coach such that everyone could see the coach and hear her voice. Moreover, there was suf- ficient space for exercising not to hit each other. After putting their hands on their knees, the subjects listened to the coach with their eyes closed. Positive thinking was implemented as follows: Take away all the negative thoughts, focus on strengths, belongings, and abilities, discover what you encounter with, such as the person, the object, and the situation, and focus and pay attention to the positive aspects of it and breathe deeply while sitting for the first 10 min and thank the creator. It was followed by the intellectual release of all mental affiliations.

The proper movements were performed for $40 \mathrm{~min}$ considering the elderly constraints, with the supervision of the coach and researcher. Standing, sitting, and lying movements were performed. The conditioning, focusing, and relaxation were performed for $10 \mathrm{~min}$. The control group did not participate in yoga classes. During the study course, they were contacted by the researcher. The subjects were referred to the service center for a doctor's appointment, and they were examined in terms of the exclusion criteria. The researcher guided participants in the control group to receive routine interventions for old people (such as controlling blood pressure and blood sugar)

The short form of the McGill pain questionnaire has three parts. The first part consists of 15 words, of which 11 words were for sensory examination, and four words were for emotional examination of pain. Each row was marked as painless, mild, moderate, and severe pain, respectively, and scored 0 to 3 ( $0=$ =painless, $1=$ mild, $2=$ moderate, and $3=$ severe). The scores were summed. The second part included VAS, which is a horizontal line with "no pain" at one end to "worst possible pain" at the other end [5]. The third part is a 6-point verbal scale, in which the patient was asked to choose from six words, being scored from none $=0$ to overwhelming $=5$. Finally, the total score of these three items was considered.

The McGill Pain Questionnaire, as a self-report questionnaire, is the most reliable instrument for measuring pain, especially resistant chronic pain. Several studies have used this questionnaire to measure elderly pain. For example, Dicorros et al. used this instrument to measure the pain in elderly females [19]. Dos Santos et al. also showed that the McGill Pain Questionnaire could effectively assess chronic pain in the elderly [20]. It has been one of the most applicable tools for more than 30 years, designed to evaluate the sensory, emotional, and pain assessment aspects. Adel Manesh et al. recommended the Persian version of McGill as a reliable, valid, and sensitive multidimensional tool to assess musculoskeletal pain [21]. 
The scientific validity of the McGill Pain Questionnaire has been evaluated in several studies in Iran. Shirazi et al. used the McGill Pain Questionnaire to assess the pain of 205 elderly patients referring to Ahwaz health centers for six months. In this study, Cronbach's alpha coefficient was 0.94 , and its reliability coefficient was 0.88 [3]. Khosrawi investigated the validity and reliability of the questionnaire in patients with cancer in 2012 and reported the Cronbach's alpha coefficient of 0.85 , and the reliability coefficient of over 0.8 in all aspects (sensory, emotional, and evaluation aspects) [22].

\section{Statistical analysis}

All statistical tests were performed using SPSS software v. 18. Quantitative data were presented as Mean \pm SD, while qualitative data were demonstrated as frequency and percentage (\%). Kolmogorov-Smirnov test was used to evaluate the normality of the data. An independent ttest was used to compare the intervention and control groups if the data were normal, and the Mann-Whitney
$\mathrm{U}$ test was used if the data had no normal distribution. To compare the changes of the two groups in the first and second months compared to before the study, if the data were not normal, Friedman test and, if normal, analysis of variance with repeated measures were used. Bonferroni post hoc test was used to compare the trend of changes in the study groups. A p-value of $<0.05$ was considered statistically significant.

\section{Data availability}

The data associated with the paper are not publicly available but are available from the corresponding author on reasonable request.

\section{Results}

The Mean \pm SD of the age was $63.5 \pm 3.67$ and $63.26 \pm 3.52$ years in the intervention and the control group, respectively; however, there was no significant difference between the two groups $(\mathrm{P}=0.80)$. Moreover,

Table 1. Demographic characteristics of the intervention and control groups

\begin{tabular}{|c|c|c|c|c|}
\hline \multirow{2}{*}{\multicolumn{2}{|c|}{ Variables }} & \multicolumn{2}{|c|}{ No.(\%) / Mean \pm SD } & \multirow{2}{*}{$\mathbf{P}$} \\
\hline & & Intervention Group ( $\mathrm{n}=30$ ) & Control Group ( $n=30)$ & \\
\hline \multirow{3}{*}{ Marital status } & Married & $26(86.6)$ & $24(80.0)$ & \multirow{3}{*}{$0.4 \varepsilon$} \\
\hline & Widow & $2(6.7)$ & $3(10.0)$ & \\
\hline & Divorced & $2(6.7)$ & $3(10.0)$ & \\
\hline \multirow[b]{2}{*}{ Job } & Housekeeper & $26(86.7)$ & $25(83.4)$ & \multirow[b]{2}{*}{2.29} \\
\hline & Employee & $4(13.3)$ & $5(16.7)$ & \\
\hline \multirow{3}{*}{ Education } & Minimum literacy & $6(20.0)$ & $10(33.3)$ & \multirow{3}{*}{1.36} \\
\hline & Elementary & $18(60.0)$ & $15(50.0)$ & \\
\hline & Secondary & $6(20.0)$ & $5(16.7)$ & \\
\hline \multirow{5}{*}{ Economic level } & Good & $14(46.7)$ & $18(60.0)$ & \multirow{5}{*}{6.03} \\
\hline & Moderate & $6(20.0)$ & $7(23.3)$ & \\
\hline & & & & \\
\hline & Poor & $9(30.0)$ & $2(6.7)$ & \\
\hline & Depended & $1(3.30)$ & $3(10.0)$ & \\
\hline \multicolumn{2}{|c|}{ Age (y) } & $63.5 \pm 3.67$ & $63.26 \pm 3.52$ & 0.80 \\
\hline \multicolumn{2}{|c|}{ Body Mass Index $\left(\mathrm{kg} / \mathrm{m}^{2}\right)$} & $30.71 \pm 3.84$ & $30.38 \pm 3.97$ & 0.74 \\
\hline \multicolumn{2}{|c|}{ Number of children } & $4.63 \pm 1.86$ & $4.1 \pm 1.90$ & 0.27 \\
\hline \multicolumn{2}{|c|}{ Duration of pain $(y)$} & $5.06 \pm 4.04$ & $5.71 \pm 4.32$ & 0.91 \\
\hline
\end{tabular}

A P-value less than 0.05 was considered to be statistically significant.

Iranian Rehabilitation Journal 
Table 2. Comparing pain-related characteristics between the intervention and control groups

\begin{tabular}{|c|c|c|c|c|}
\hline \multirow{2}{*}{\multicolumn{2}{|c|}{ Variables }} & \multicolumn{2}{|c|}{ No.(\%) } & \multirow{2}{*}{ P-Value } \\
\hline & & Intervention Group(n=30) & Control Group(n=30) & \\
\hline \multirow{3}{*}{ Hospitalization } & Yes & $21(70.0)$ & $19(63.3)$ & \multirow{3}{*}{0.30} \\
\hline & & & & \\
\hline & No & $9(30.0)$ & $11(36.7)$ & \\
\hline \multirow{3}{*}{ History of fractures } & Yes & $7(23.3)$ & $8(26.7)$ & \multirow{3}{*}{0.08} \\
\hline & & & & \\
\hline & No & $23(76.7)$ & $22(73.3)$ & \\
\hline \multirow{7}{*}{ Location of fractures } & neck & $6(20.0)$ & $6(20.0)$ & \multirow{7}{*}{1.59} \\
\hline & Hand & $3(10.0)$ & $3(10.0)$ & \\
\hline & Shoulder & $4(13.3)$ & $5(16.7)$ & \\
\hline & & & & \\
\hline & Waist & $2(6.7)$ & $2(6.7)$ & \\
\hline & Knee & $11(36.7)$ & $10(33.3)$ & \\
\hline & leg & $4(13.3)$ & $4(13.3)$ & \\
\hline \multirow{3}{*}{ Pain relief factors } & movement & $20(66.7)$ & $23(76.7)$ & \multirow{3}{*}{0.82} \\
\hline & sleeping & $5(16.7)$ & $4(13.3)$ & \\
\hline & sitting & $5(16.7)$ & $3(10.0)$ & \\
\hline
\end{tabular}

A P-value less than 0.05 was considered to be statistically significant.

Mranian Rehabilitation Journal

elementary education level was reported as the highest level of education in both intervention and control groups $(60 \%$ in the intervention group and $50 \%$ in the control group). The Mean \pm SD duration of pain was $5.06 \pm 4.04$ in the intervention group and $5.71 \pm 4.32$ in the control group. Also, the Mean \pm SD of Body Mass Index (BMI) was $30.71 \pm 3.84 \mathrm{~kg} / \mathrm{m}^{2}$ in the intervention group and $30.38 \pm 3.97 \mathrm{~kg} / \mathrm{m}^{2}$ in the control group. Nonetheless, there was no statistically significant difference between the two groups regarding demographic factors, duration of pain, and BMI (Table 1). Pain-related characteristics included hospitalization and location and history of fractures, and pain relief factors between intervention and control groups. Based on the findings, there was no statis-

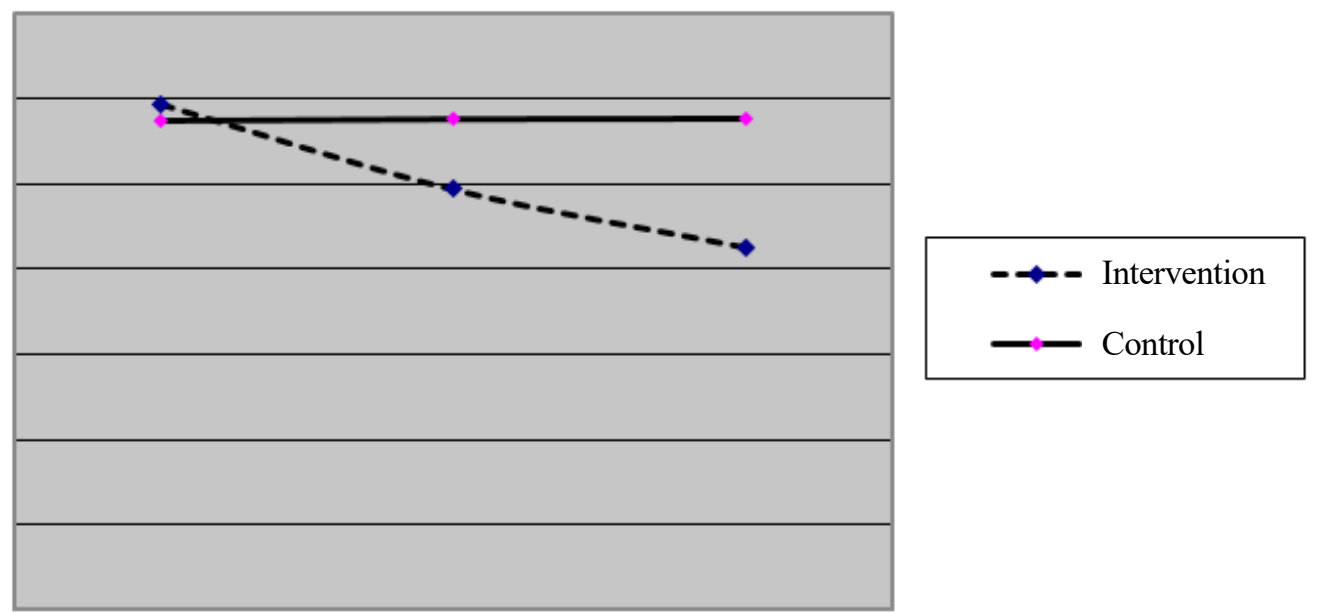

Mranian Rehabilitation Journal

Figure 2. Comparison of the mean total pain in the intervention and control groups before and after four and eight weeks of the studyl 
Table 3. Mean total pain and its subscales scores before and at the end of the $4^{\text {th }}$ and $8^{\text {th }}$ weeks between the groups

\begin{tabular}{|c|c|c|c|c|c|}
\hline \multirow{2}{*}{ Variables } & \multirow{2}{*}{ Groups } & \multicolumn{3}{|c|}{ Mean $\pm S D$} & \multirow{2}{*}{$\stackrel{\text { P }}{\text { (Within-Group) }}$} \\
\hline & & Before & Fourth Week & Eighth Week & \\
\hline \multirow{2}{*}{ Sensory pain } & Intervention & $17.16 \pm 4.92$ & $15.06 \pm 4.75$ & $13.53 \pm 4.73$ & 0.0001 \\
\hline & control & $17.00 \pm 4.54$ & $17.13 \pm 4.47$ & $17.23 \pm 4.5$ & 0.283 \\
\hline \multicolumn{2}{|c|}{ P-value (Between-group) } & $0.89^{* *}$ & $0.053^{*}$ & $0.001^{*}$ & - \\
\hline \multirow{2}{*}{ Emotional pai } & Intervention & $4.80 \pm 1.93$ & $3.43 \pm 1.79$ & $2.53 \pm 1.54$ & $0.0001^{* * *}$ \\
\hline & control & $4.36 \pm 1.27$ & $4.37 \pm 1.27$ & $4.40 \pm 1.33$ & $0.891^{* * *}$ \\
\hline \multicolumn{2}{|c|}{ P-value (Between-group) } & $0.45^{*}$ & $0.026^{*}$ & $0.0001^{*}$ & - \\
\hline \multirow{2}{*}{ VAS } & Intervention & $5.35 \pm 1.13$ & $4.50 \pm 1.14$ & $3.92 \pm 1.30$ & 0.0001 \\
\hline & control & $5.02 \pm 1.14$ & $5.05 \pm 1.16$ & $5.06 \pm 1.15$ & 0.267 \\
\hline \multicolumn{2}{|c|}{ P-value (Between-group) } & $0.17^{*}$ & $0.069^{* *}$ & $0.001^{* *}$ & - \\
\hline \multirow{2}{*}{ Current pain } & Intervention & $2.40 \pm 0.77$ & $1.70 \pm 0.70$ & $1.30 \pm 0.59$ & $0.0001^{* * *}$ \\
\hline & control & $2.26 \pm 0.73$ & $2.26 \pm 0.73$ & $2.16 \pm 0.69$ & 0.065 \\
\hline \multicolumn{2}{|c|}{ P-value (Between-group) } & $0.60^{*}$ & $0.005^{*}$ & $0.0001^{*}$ & - \\
\hline \multirow{2}{*}{ Total pain } & Intervention & $29.72 \pm 7.19$ & $24.70 \pm 7.00$ & $21.29 \pm 6.91$ & 0.0001 \\
\hline & control & $28.65 \pm 6.37$ & $28.82 \pm 6.27$ & $28.87 \pm 6.25$ & 0.46 \\
\hline \multicolumn{2}{|c|}{ P-value (Between-group) } & $0.54^{* *}$ & $0.019^{* *}$ & $0.0001^{* *}$ & - \\
\hline
\end{tabular}

A P-value less than 0.05 was considered to be statistically significant.

Iranian Rehabilitation Journa

"Mann Whitney U test, ${ }^{* *}$ Independent t-test, ${ }^{* * *}$ Friedman test

tically significant difference between the two groups in terms of hospitalization $(\mathrm{P}=0.30)$ and location $(\mathrm{P}=1.59)$ and history of fractures $(\mathrm{P}=0.80)$, and pain relief factors $(\mathrm{P}=0.82)$. According to the findings, $70 \%$ in the intervention group and $63.30 \%$ in the control group had a history of hospitalization for various reasons. Also, the findings of the study indicated that 23 patients in the intervention group (76.7\%) and 22 in the control group (73.3\%) did not mention the history of fractures. Moreover, the knee was reported as the most common pain area of location in both intervention and control groups $(36.70 \%$ in the intervention group and $33.30 \%$ in the control group). The most pain-intensifying agent was movement in both intervention and control groups $(66.7 \%$ in the intervention group and $76.7 \%$ in the control group) (Table 2).

The findings related to the pain and its subscales indicated that before the intervention, the average pain in the intervention group was $29.72 \pm 7.19$ and in the control group was $28.65 \pm 6.37$, and there was no significant difference between the two groups $(\mathrm{P}=0.54)$. The average of the pain subscales before the intervention was similar between the two groups. The statistical test did not show any significant difference between the two groups before the intervention in this regard $(\mathrm{P}>0.05)$. At the end of the fourth week after the intervention, the Mean \pm SD pain

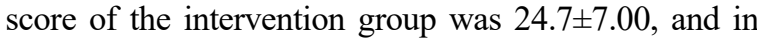
the control group, it was $28.82 \pm 6.27$. Furthermore, the emotional and current pain subscales were further reduced in the intervention group compared to the control group, indicating pain relief in this group. The statistical test showed a significant difference between the two groups before and at the end of the fourth week in terms of mean total pain $(\mathrm{P}=0.019)$ and subscales of emotional $(\mathrm{P}=0.026)$ and current pain aspects $(\mathrm{P}=0.005)$. According to the independent $t$-test and Mann-Whitney test, the subscales of sensory pain aspect $(\mathrm{P}=0.053)$ and pain severity $(\mathrm{P}=0.069)$ in the two groups before and at the end of the fourth week did not differ significantly. At the end of the eighth week after the intervention, the Mean \pm SD pain score of the intervention group was $21.29 \pm 6.91$ and in the control group was $28.87 \pm 6.25$. At the end of 
Table 4. Comparison of the difference between the mean total pain scores in the fourth and eighth weeks

\begin{tabular}{|c|c|c|c|c|c|c|c|}
\hline \multicolumn{8}{|c|}{ Pairwise Comparisons } \\
\hline \multirow{2}{*}{ Groups } & \multirow{2}{*}{ Pain (I) } & \multirow{2}{*}{ Pain (J) } & \multirow{2}{*}{$\begin{array}{c}\text { Mean } \\
\text { Difference (I-J) }\end{array}$} & \multirow{2}{*}{ Std. Error } & \multirow{2}{*}{ Sig. ${ }^{b}$} & \multicolumn{2}{|c|}{ 95\% Confidence Interval for Difference } \\
\hline & & & & & & Lower Bound & Upper Bound \\
\hline \multirow[b]{2}{*}{ Intervention } & \multirow[b]{2}{*}{ Before } & Fourth week & $5.023^{*}$ & 0.358 & 0.0001 & 4.141 & 5.906 \\
\hline & & Eighth week & $8.430^{*}$ & 0.570 & 0.0001 & 7.025 & 9.835 \\
\hline \multicolumn{2}{|c|}{ Fourth week } & Eighth week & $3.407^{*}$ & 0.302 & 0.0001 & 2.662 & 4.151 \\
\hline \multirow{2}{*}{ Control } & \multirow{2}{*}{ Before } & Fourth week & -0.170 & 0.358 & 1.000 & -1.053 & 0.713 \\
\hline & & Eighth week & -0.213 & 0.570 & 1.000 & -1.618 & 1.191 \\
\hline \multicolumn{2}{|c|}{ Fourth week } & Eighth week & -0.043 & 0.302 & 1.000 & -0.788 & 0.701 \\
\hline
\end{tabular}

Iranian Rehabilitation Journal

the eighth week, all pain subscales in the intervention group decreased compared to the control group. The independent t-test and Mann-Whitney test showed a significant difference between the overall score of the pain $(\mathrm{P}=0.0001)$ and its subscales, including emotional and current pain ( $\mathrm{P}=0.0001)$, sensory pain $(\mathrm{P}=0.001)$, and pain severity $(\mathrm{P}=0.001)$ (Table 3$)$. The total mean pain score in intervention and control groups at the end of the fourth and eighth weeks of the study compared to the baseline. As shown in Figure 2, a descending pain trend was observed in the intervention group indicating the decreased pain in the intervention group. The findings related to the intra-group comparison between the intervention and control groups showed that the mean of pain and its subscales in the intervention group at the end of the fourth and eighth weeks decreased compared to the pre-intervention condition indicating the pain relief compared to the baseline $(\mathrm{P}=0.0001)$ (Table 3). Friedman and ANOVA with repeated measures showed a significant difference between the fourth and eighth weeks compared to the baseline $(\mathrm{P}=0.0001)$. However, in the control group, the mean total pain and its subscales did not change at the end of the fourth and eighth weeks compared to the baseline (Table 4).

\section{Discussion}

In this study, all types of musculoskeletal pain in healthy elderly were considered. In many studies, the effect of yoga was considered only on a painful region. For example, Akbari et al. [11] assessed the effect of yoga and common exercises on depression, pain, functional disability, and lumbar motion domain in females aged 28 to 60 years with a lumbar disc herniation. The findings of this study showed that yoga effectively reduced the backache caused by lumbar disc herniation. Despite the differences between this study and the present study, in terms of the type of pain, sample size, number of yoga sessions, and pain evaluation tools, the findings of the two studies are consistently indicating the effect of yoga on acute pain and in younger people in a certain position similar to chronic musculoskeletal pain in old people. However, Teut et al. [15] compared the effects of yoga and traditional Qigong medicine on chronic back pain in elderly aged 65 years and older and reported that yoga did not relieve back pain. This finding is not consistent with the findings of the current study. In the mentioned study, participants were complaining of back pain for 18 to 20 years, and $60 \%$ of the subjects took medication. In the present study, the mean duration of pain was five years. The reason for this difference in the results of this study can be due to the area of the pain in these two studies and the long duration of lower back pain in Theo Michelle et al.'s study.

The current research results suggested that the eight weeks of yoga practicing reduced all dimensions of pain based on the McGill Pain Scale decreased further during eight weeks compared to the four weeks in elderly females. In the study by Park et al. in 2017, the severity of pain decreased further during three months compared to the eight weeks [16]. This result suggests that more time is required to indicate the effects of yoga on all aspects of pain. Yoga exercises do not improve all aspects of pain in the short term, and yoga exercises for a long time are required in this regard.

The findings of this study showed that the most painful zone was in the knee area, and the average BMI of the elderly was above 30. In a study conducted by Shirazi et al. on the prevalence of musculoskeletal pain in the elderly, it was also reported that the knee was the most frequent region 
of pain, followed by the neck, shoulder, waist, and hands [3]. Considering the culture of traditional Iranian society, in many activities, such as sitting on the ground and using the Iranian toilet, the knee bends more than 90 degrees. In this situation, a huge deal of stress is applied to the knee. These stresses will be associated with damage to the knee structures related to tibiofemoral and patellofemoral joints and will eventually lead to pain and disability [4]. Also, in the study by Alipour et al., elderly with a BMI of more than 30 had significantly more pain than other elderly. Knee pain resulted in reduced movement and increased weight. Again, weight gain leads to more pressure on the knee [23].

One of the limitations of this study is the lack of longterm follow-up. Future studies with consistent follow-up for a longer duration could be planned to explore the substantial and constraint effect of yoga. Although several studies have reported similar findings, the type and time of yoga practice varied between studies, and hence, the effect might also vary according to the design of the study.

\section{Conclusion}

According to this study, yoga exercise may significantly reduce musculoskeletal pain and some subscales of the McGill Pain Scale, including sensory dimension and severity of pain in older females after eight weeks. Thus, yoga exercise for eight weeks may be recommended as a non-pharmacological treatment option to improve musculoskeletal pain in older females.

\section{Ethical Considerations}

\section{Compliance with ethical guidelines}

This study was approved by the Ethics Committee of the Rafsanjan University of Medical Science (Code: IR.RUMS.REC.1396.216).

\section{Funding}

This research was funded by a grant from the Vice Chancellery for Research \& Technology of Rafsanjan University of Medical Sciences.

\section{Authors' contributions}

All authors equally contributed to preparing this article.

\section{Conflict of interest}

The authors declared no conflict of interest.

\section{Acknowledgments}

We would like to thank the responsible authorities of the Geriatric Care Research Center and the Vice Chancel- lery for Research and Technology of Rafsanjan University of Medical Sciences, Iran, which funded this study.

\section{References}

[1] Golamrej Eliasi L, Addelyan Rasi H, Tavakoli A. Factors affecting quality of life among elderly population in Iran. Humanities and Social Sciences. 2017; 5(1):26-30. https://www. researchgate.net/profile/Laleh-Golam.pdf

[2] Bernfort L, Gerdle B, Rahmqvist M, Husberg M, Levin LÅ. Severity of chronic pain in an elderly population in Swedenimpact on costs and quality of life. Pain. 2015; 156(3):521-7. [DOI:10.1097/01.j.pain.0000460336.31600.01] [PMID]

[3] Shirazi M, Manoochehri H, Zagheri Tafreshi M, Zayeri F, Alipour V. Prevalence of chronic pain and its characteristics among elderly people in Ahvaz city: A cross sectional study. Journal of Geriatric Nursing. 2015; 2(1):62-78. https://jgn medilam.ac.ir/article-1-159-en.pdf

[4] Taghipour M, Hosseini SR, Kia K, Abbaspour M, Ghadimi R. [Prevalence of musculoskeletal pain and it's correlation to functional disability in elderly (Persian)]. Knowledge and Health. 2013; 8(2):76-82. http://knh.shmu.ac.ir/index.php/ site/article/view/50

[5] de Kruijf M, Stolk L, Zillikens MC, de Rijke YB, BiermaZeinstra SMA, Hofman A, et al. Lower sex hormone levels are associated with more chronic musculoskeletal pain in community-dwelling elderly women. Pain. 2016; 157(7):142531. [DOI:10.1097/j.pain.0000000000000535] [PMID]

[6] Treede RD, Rief W, Barke A, Aziz Q, Bennett MI, Benoliel $\mathrm{R}$, et al. A classification of chronic pain for ICD-11. Pain. 2015; 156(6):1003-7. [DOI:10.1097/j.pain.0000000000000160] [PMID] [PMCID]

[7] Sit RWS, Choi SYK, Wang B, Chan DCC, Zhang D, Yip BHK, et al. Neuromuscular exercise for chronic musculoskeletal pain in older people: A randomised controlled trial in primary care in Hong Kong. The British Journal of General Practice: The Journal of The Royal College of General Practitioners. 2021; 71(704):e226-36. [DOI:10.3399/bjgp20X714053] [PMID] [PMCID]

[8] Ravari A, Mirzaei T, Bahremand R, Raeisi M, Kamiab Z The effect of Pilates exercise on the happiness and depression of elderly women: A clinical trial study. The Journal of Sports Medicine and Physical Fitness. 2021; 61(1):131-9. [DOI:10.23736/S0022-4707.20.10730-8] [PMID]

[9] Field T. Knee osteoarthritis pain in the elderly can be reduced by massage therapy, yoga and tai chi: A review. Complementary Therapies in Clinical Practice. 2016; 22:87-92. [DOI:10.1016/j.ctcp.2016.01.001] [PMID]

[10] Irandoust K, Taheri M. [The impact of yoga and pilates exercises on older adults (Persian)]. Salmand: Iranian Journal of Ageing. 2016; 11(1):152-61. [DOI:10.21859/sija-1101152]

[11] Akbari A, Rezaei S. [The effect of yoga exercises on lumbar range of motion, pain and functional disability in women with chroniclumbar disk herniation: A randomized controlled study (Persian]. Journal of Ilam University of Medical Sciences. 2012; 20(3):16-28. http://sjimu.medilam.ac.ir/article11-775-en.html. 
[12] Lee M, Moon W, Kim J. Effect of yoga on pain, brain-derived neurotrophic factor, and serotonin in premenopausal women with chronic low back pain. Evidence-Based Complementary and Alternative Medicine: eCAM. 2014; 2014:203173. [DOI:10.1155/2014/203173] [PMID] [PMCID]

[13] McCaffrey R, Park J. The benefits of yoga for musculoskeletal disorders: A systematic review of the literature. Journal of Yoga \& Physical Therapy. 2012; 2:122. https:/ / www.longdom.org/abstract/the-benefits-of-yoga-for-musculoskeletaldisorders-a-systematic-review-of-the-literature-42188.html

[14] Büssing A, Ostermann T, Lüdtke R, Michalsen A. Effects of yoga interventions on pain and pain-associated disability: A meta-analysis. The Journal of Pain. 2012; 13(1):1-9. [DOI:10.1016/j.jpain.2011.10.001] [PMID]

[15] Teut M, Knilli J, Daus D, Roll S, Witt CM. Qigong or yoga versus no intervention in older adults with chronic low back pain-a randomized controlled trial. Journal of Pain. 2016; 17(7):796-805. [DOI:10.1016/j.jpain.2016.03.003] [PMID]

[16] Park J, McCaffrey R, Newman D, Liehr P, Ouslander JG. A pilot randomized controlled trial of the effects of chair yoga on pain and physical function among community-dwelling older adults with lower extremity osteoarthritis. Journal of the American Geriatrics Society. 2017; 65(3):592-7. [DOI:10.1111/ jgs.14717] [PMID] [PMCID]

[17] Fallah Mehrabadi E, Pakgohar M, Asadi S, Haghani H. [Lifestyle of elderly people with osteoporosis and its related factors (Persian)]. Salmand: Iranian Journal of Ageing. 2017; 12(2):132-45. [DOI:10.21859/sija-1202132]

[18] Tanhaee Z, Fathi-Ashtiani A, Amini M, Vahedi H, Shaghaghi F. [Validation of a revised version of the Short-form Mc-Gill Pain Questionnaire (SF-MPQ-2) for IBS patients (Persian)]. Govaresh. 2012; 17(2):91-6. https://www.sid.ir/fa/ journal/ViewPaper.aspx?id=199003

[19] de Queiroz BZ, Pereira DS, Lopes RA, Felício DC, Silva JP Rosa NM, et al. Association between the plasma levels of mediators of inflammation with pain and disability in the elderly with acute low back pain: Data from the Back Complaints in the Elders (BACE)-Brazil study. Spine. 2016; 41(3):197-203. [DOI:10.1097/BRS.0000000000001214] [PMID]

[20] dos Santos CC, Pereira LS, de Resende MA, Magno F, Aguiar V. [Application of the Brazilian version of the Mcgill Pain Questionnaire to elderly people with chronic pain (Portuguese)]. Acta Fisiátrica. 2006; 13(2):75-82. [DOI:10.5935/01047795.20060002]

[21] Adelmanesh F, Arvantaj A, Rashki H, Ketabchi S, Montazeri A, Raissi G. Results from the translation and adaptation of the Iranian Short-Form McGill Pain Questionnaire (I-SF-MPQ): Preliminary evidence of its reliability, construct validity and sensitivity in an Iranian pain population. Sports Medicine, Arthroscopy, Rehabilitation, Therapy \& Technology: SMARTT. 2011; 3(1):27. [DOI:10.1186/1758-2555-3-27] [PMID] [PMCID]

[22] Khosravi M, Sadighi S, Moradi Sh, Zendehdel K. [PersianMcGill pain questionnaire translation, adaptation and reliability in cancer patients: A brief report (Persian)]. Tehran Universiity Medical Journal. 2013; 71(1):53-8. http://tumj. tums.ac.ir/article-1-38-en.html
[23] Alipour M, Hosseini S, Saadat P, Bijani A. The relationship between chronic musculoskeletal pain and vitamin $\mathrm{D}$ deficiency in the elderly population of Amirkola, Iran. Journal of Babol University of Medical Sciences. 2015; 17(10):7-14. http://jbums.org/article-1-5581-en.html 